\title{
Economic burden of moderate to severe burns and its association with health-related quality of life of Nigerian women
}

Anthonia U. Chinweuba ${ }^{1 *}$ (D), Ifunanya S. Chinweuba ${ }^{2}$, Faith C. Diorgu ${ }^{3}$, Nneka E. Ubochi ${ }^{1}$, Chinwe S. Ezeruigbo ${ }^{4}$, Kenneth B. Wasini ${ }^{5}$ and Anthonia I. Nnabuenyi ${ }^{6}$

\begin{abstract}
Background: Burns cases are frequent in Nigeria hospitals, however, literature on its economic burden and the association with health-related quality of life (HRQOL) of women in Nigeria is scarce. This study determined the burden of hospitalization after burns on women's economic status and its associated HRQOL.

Methods: This was a three-month cross-sectional study of female patients $\geq 25$ years, treated of mixed or full thickness burns in four teaching hospitals in south-east Nigeria, discharged between September-November, 2018. Study instruments were participants' case notes for socio-demographic and disease history, interviewer-administered questionnaires, namely-economic-burden-of-burns questionnaire and English version of the EuroQol Five-DimensionsThree-Level Health Questionnaire for Nigeria. Data were collected on second- or third-day post-discharge through home visits or phone calls. This lasted for 13 weeks.
\end{abstract}

Results: A total of seventy-three female patients with burn were successfully enrolled. Most participants were married, fairly educated, mainly traders or housewives. Thirty-four (46.6\%) had subjective estimated family monthly income below NGN 50,000 (low economic status). Participants' average monthly income reduced drastically after hospitalization. Their average family monthly income was NGN110,439 (USD307), while their average total expenses incurred during hospitalization was NGN691,093 (USD1,920). Almost all (93.2\%) had at least one surgical intervention during management. Their average length of hospital stay was 35.4 days; eleven consequently lost their job. Many had moderate to severe economic burden of treatment; only eleven could bear all the treatment expenses independently. Anxiety/depression and pain/discomfort were common problems reported, However, these Euroqol dimensions varied according to their SES, education and occupation. Women in the low economic class were more inclined to poor HRQOL (Mean \pm SD VAS $=53.33 \pm 17.619)$ than women in high economic class (Mean \pm SD VAS $=76.67 \pm 21.794)$.

Conclusion: Burns places high level of economic burden on women and unfortunately, Nigerian government's commitment to healthcare of burns patients is low. The long course of hospitalization and economic depletion impact negatively on the women's HRQOL. Based on these findings, we recommend that government parastatals create special trust fund for burns treatment and the National Health Insurance Scheme be restructured for more accessibility.

\footnotetext{
*Correspondence: anthonia.chinweuba@unn.edu.ng

${ }^{1}$ Department of Nursing Sciences, Faculty of Health Sciences

and Technology, College of Medicine, University of Nigeria, Enugu

Campus, Enugu, Nigeria

Full list of author information is available at the end of the article
}

(C) The Author(s) 2021. Open Access This article is licensed under a Creative Commons Attribution 4.0 International License, which permits use, sharing, adaptation, distribution and reproduction in any medium or format, as long as you give appropriate credit to the original author(s) and the source, provide a link to the Creative Commons licence, and indicate if changes were made. The images or other third party material in this article are included in the article's Creative Commons licence, unless indicated otherwise in a credit line to the material. If material is not included in the article's Creative Commons licence and your intended use is not permitted by statutory regulation or exceeds the permitted use, you will need to obtain permission directly from the copyright holder. To view a copy of this licence, visit http://creativecommons.org/licenses/by/4.0/. The Creative Commons Public Domain Dedication waiver (http://creativeco mmons.org/publicdomain/zero/1.0/) applies to the data made available in this article, unless otherwise stated in a credit line to the data. 
Keywords: Burns, Economic burden, Economic status, Health expenditure, Hospitalization, Quality of life

\section{Background}

Burn injury is a major public health concern. It is characterized as skin and/or other organic tissue injury caused primarily by extreme heat. Burn injury is ranked fourth in common traumatic conditions after traffic accident, falls and interpersonal violence [1]. An estimated 180,000 global annual deaths occur due to fire-related burn injuries, $95 \%$ of which were in low- and middle-income countries [2]. Non-fatal burns have been noted to be leading cause of morbidity, prolonged hospitalization and disability [2], which may affect one's health-related quality of life (HRQOL). Health-related quality of life represents a self-report of one's perceived feeling of satisfaction with life, comfort and ability to realize one's life potentials. HrQoL is closely linked with responsibilities of an individual.

Cases of burn injury are frequently recorded in Nigeria hospital. Although few literatures have evaluated the impact and cost of managing burns in Nigeria $[3,4]$, there is still dearth of literature on economic burden of burns and its association with HRQOL of burns, especially female patients in this part of the world where women are exposed to a lot of socio-economic challenges [5, 6]. Enyioha [7] noted fast changing economic roles of African women as the world turns into a global village. These responsibilities translate to the amount of burden or difficulty the woman experiences. Severity of burn injury, depression, post-traumatic stress symptoms, inadequate social support, and loss of employment after hospitalization have been identified as predictors of poor HRQOL after burns [8], Economic hardship in women is directly proportional to their health trajectories [9]. Older women with lower socio-economic status and higher family/ career responsibilities have lower HRQOL [10]. Similarly, homemakers who are often financially dependent experience more economic hardship than the career women that are relatively less financially dependent [11].

The economic drain on the patient's purse due to burns treatment is huge especially in developing countries, with a mean hospital cost of about USD2,766 (NGN1,002,675) and a range from USD143 to USD33,566 (NGN51,480NGN12,083,760) [12-14]. Studies in Nigeria have shown that the average length of hospital stay (LHS) for burn management was 19 days, the average daily cost of treatment per patient was USD47.74 [15] and the total cost of management was USD7,123.28 per patient [5]. However, Nigeria's average daily income per person is less than USD1 [16] and health insurance scheme is almost nonexistent [17-19]. The Nigerian National Health Insurance
Scheme (NHIS) is a social security system launched formally in 2006 the aim of which is to improve the health of all Nigerians by increasing access to universal healthcare, providing healthcare at an affordable cost through various prepayment systems. This scheme is meant to provide equal access to health care across different income classes and reduce the out of pocket expenditure on healthcare by the insured through contributions by the insurer, usually the federal government [20]. This high cost of care has been attributed to series of surgeries and long hospitalization with accompanying huge out-ofpocket expenditures [4, 21-23].

The aim of the study was to determine the economic burden of hospitalization after burns on patients. Specific objectives were to: assess the cost of hospitalisation after burns; assess the sources of fund for medical and nonmedical expenses available to the women; and, determine the women's HRQOL based on the economic burden of burns management. It was hypothesized in this study that there is no significant association between the women's socio-economic status and their HRQOL. This study will contribute to literature pools for economic evaluation of burns treatment.

\section{Methods}

This was a three-month cross-sectional descriptive study of adult female patients admitted in hospitals, treated of burns and were discharged between 1st September and 30th November, 2018. Cross-sectional descriptive study had been used successfully in similar studies [10, 24]. The study was carried out in four teaching hospitals in southeast Nigeria. Inclusion criteria were: women $\geq 25$ years, treated of mixed or full thickness accidental burns $(\geq 30 \%$ total surface burn area according to the Rule of Nines for estimating burn percentage in adults), who were mentally stable and gave voluntary consent to participate.

A total of 89 women with burn injury were on admission in the four hospital at the time of study. A sample size of 72 women was initially estimated using the Creative Research Systems survey software's sample size calculator formula: $s s=\left(Z^{2 *}(\mathrm{p}) *(1-\mathrm{p})\right) / C^{2}$; where: $\mathrm{Z}=1.96$, $\mathrm{p}=$ proportion of target population (women $\geq 25$ years old, estimated to have $>30 \%$ total surface burn area) (expressed as 0.5), $\mathrm{C}=$ Confidence Interval $(0.04 \pm 4)$ [25]. Applying the adjusted sample size formula for anticipated $10 \%$ attrition rate: $x=\mathrm{ss} / 1-\mathrm{f}$ (where $x$ is adjusted sample size; ss is original sample size; and, $\mathrm{f}$ is estimated non-response rate) [26], this initial sample size estimate was adjusted from 72 to 80 representing about $89.9 \%$ of 
the population. The flow chart of eligible patients and participants is presented in Fig. 1.

\section{Instrument for data collection}

In this study, HRQOL is based on scores obtained on the European quality of life-five dimensions three levels instrument (EuroQol-5D-3L). Participants' case notes and interview-administered questionnaire developed in three parts were used. Part A collected eleven data on socio-demographic profile of participants and their clinical parameters namely: phone number, residential address, age, marital status, parity, education, occupation, estimated family monthly income (FMI), pre-hospital treatment, number of surgeries done and other co-morbidities. Part B was researcher-developed economic burden of burns questionnaire (EBB-Q) adapted from Deshpande, Puri, Vora, Shende and Choudhary [27] with nine items. Deshpande and colleagues formulated the EBB-Q to guide their data collection in a retrospective study on how families of patients cope with socio-economic burden of burns. The socio-demographic profile of participants, their clinical parameters and the researcher-developed EBB-Q are provided as Additional File 1. To determine the existence of economic gradient in HRQOL of women who had burns, participants were assigned social status based on their estimated FMI. Thus, women with estimated FMI less than NGN50,000 $(<$ USD139) were classified as low economic status

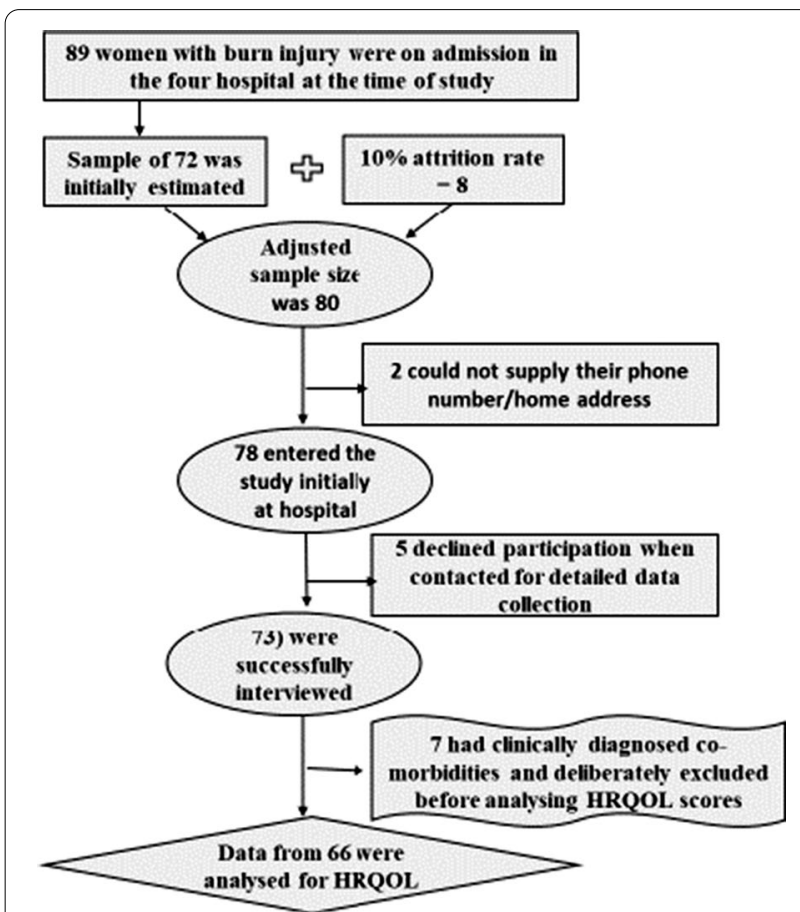

Fig. 1 Flowchart of eligible patients and participants
(LES), NGN50,000-NGN300,000 (USD139 to USD834)/ month-middle economic status (MES), and more than NGN 300,000 (> USD834)/month-high economic status (HES). Cost of hospitalization include direct medical and other (subjective) non-medical expenditures incurred as a result of the burn treatment. Direct medical costs include costs of medications and consumables, surgeries, investigations, blood products, nursing care and bed space. Indirect costs include dietary cost, transportation costs by caregivers and other incidental expenses. Direct costs are billable; hence, direct costs were obtained from respective patient's case notes. Indirect costs were estimates provided by the respondent during interview. Part $\mathrm{C}$ was EuroQol Five-Dimensions-Three-Level (EQ5D-3L) Health Questionnaire for face-to-face and telephone methods. English version of the EQ-5D-3L for Nigeria and license to use same were obtained from the Euroqol Foundation through formal email. The EQ5D-3L is a generic, preference-based measure of health with five dimensions, namely: mobility, self-care, usual activities, pain/discomfort, and anxiety/depression; and three levels of health state coded 1-3. Where: $1=$ no problem, $2=$ Moderate problem and $3=$ extreme problem. It also contains a EuroQol visual analogue scale (EQ VAS) that requires the respondent to indicate the point on the scale where she would put her 'own health state today' ranging from ' 0 ' (the worst health she can imagine) to ' 100 ' (the best health she can imagine). Validity of the EQ-5D-3L in burns patients was established by Oster, Willebrand, Dyster-Aas, Kildal and Ekselius [28]. The Head of Department of Health Administration and Management, University of Nigeria, Nsukka was requested to evaluate the readability, relevance and feasibility of the EBB-Q and the socio-demographic profiles /clinical parameters. Also, a professor in Medical-Surgical Nursing in the Department of Nursing Sciences, University of Nigeria, Nsukka and a plastic surgeon from Burns and Plastic Unit of the National Orthopaedic Hospital, Enugu were presented with the instrument and requested to help in ascertaining that all relevant items were included in the EBB-Q and socio-demographics. All necessary corrections were subsequently effected. For internal consistency reliability test of the instruments, copies were administered to eight newly discharged burns patients at the Burns and Plastic female ward of the University of Nigeria Teaching Hospital, Ituku-Ozalla between 4 and 11th of August, 2018, representing 10\% of the sample size, after due consent. Applying split-half method, the scores were computed using Cronbach Alpha reliability test. Reliability coefficient (r) of 0.88 for Part A, 0.79 for Part B, and 0.93 for Part $C$ were considered satisfactory.

As some of the participants might not communicate effectively in English Language, an Ibo linguist was 
requested to translate the instrument to the local dialect $(I b o)$; another linguist was asked to translate the $I b o$ version to English Language without recourse to the original instrument. The translated English Language version was correlated with the original and discrepancies resolved in the local dialect version before use on the participants.

\section{Ethical consideration}

Ethical approval to conduct the study was obtained from the Health Research Ethics Committee of the National Orthopaedic Hospital, Enugu (IRB/HEC Number: RET/313/111/988). In addition, administrative permit was sought from Heads of Nursing Services and Ward Heads of female burns and plastic wards of the respective hospitals. Written informed consent was obtained from participants before enrolment. Purpose of the study and role of participants were fully explained to the prospective participants prior to the consent. They were also assured of anonymity and confidentiality in data collection and use. Only women who gave consent were enrolled into the study.

\section{Procedure for data collection}

With the assistance of clinicians in the female burns and plastic wards of the hospitals, researcher approached prospective participants already on admission. Purpose of the study and role of participants were explained to them while they were assured of confidentiality of information and non-maleficence. They were informed that researcher would visit them at their home two to three days after discharge from hospital for data collection. Cell phone numbers were exchanged with consenting patients to enhance communication. Data were collected at two points in time as follows:

Point 1, participant's socio-demographic and disease history were elicited from their case notes at the time of discharge. Participants were identified using serial numbers assigned to their hospital file numbers and cell phone numbers (where available) for confidentiality. Thereafter, participants were asked to indicate if they would prefer to be visited physically at home or to have telephone call interview for data collection after discharge home. Two could not supply their phone number and/or home address and were excluded.

Point 2: Interviewer contacted participants between the 2nd and 3rd day after returning home for face-toface or telephone call interview as pre-arranged. Only six opted for telephone calls. Member of the team visited the remaining seventy-two at their homes. For face-to-face method, interviewer established rapport, arranged for comfortable seats for the two, placed a copy of the questionnaire in front of him/her and gave a second copy to the participant for reference (where necessary). The interviewer read out contents of the questionnaire to the respondent item by item, using the preferred language version (English or $I b o$ ) and entered participant's answers directly into the questionnaire. They were asked questions about their 'own health state today' and requested to rate their health on a measuring scale, emphasizing honesty. To avoid bias, a question was only repeated word for word when participant asked for clarification. Interviewer's personal explanations were avoided; instead, participant was asked to use her own interpretation and answer in a way that most closely resembled her thoughts about her 'health state today'. The interview took 15-30 min to complete. Seventy-eight (78) patients entered the study initially while seventy-three (73) were successfully interviewed representing $93.6 \%$ of the population. The remaining five declined participation when contacted for detailed data collection. Data collection lasted for twelve weeks and five days.

\section{Statistical analysis}

Data were analysed descriptively using frequencies, percentages, mean and standard deviation, and presented using contingency tables. Data collected on the estimated FMI and expenses due to burns and treatment were used to describe the economic burden of hospitalization after burns on the women's economic life. Descriptive statistics of number, percentages, mean and standard deviation were used to report the health profile of the participants on each level of problem on each dimension of the EQ-5D-3L as affected by their condition [29]. At three-points scale, any mean $\geq 2$ was considered a high level of problem and poor HRQOL. Level of health state of participants was established by determining the utility scores on the EQ-5D-3L scales according to their sociodemographic characteristics. To determine the economic burden of the burns, analysis of variance (ANOVA) was performed on the subjective degree of worsening of economic status due to burns and hospitalisation. ANOVA was used to analyse the association between the scores on the EQ-5D-3L VAS HRQOL of the women and their socio-economic status; and Tukey HSD applied for Post Hoc test of homogeneity of the scores where they existed. All statistical analyses were performed using the statistical package for social sciences version 23.0 computer software programme (SPSS inc., IL: Chicago, USA) at $95 \%$ confidence interval.

\section{Results}

Seventy-three (73) post burns patients finally entered the study (Fig. 1). 


\section{Patient characteristics}

Table 1 showed that 34 (46.6\%) out of the 73 women that entered the study had subjective estimated FMI below NGN50,000 (LES). Only 12 (16.4\%) were classified as HES. Majority 45 (61.6\%) were married. Half of the participants $37(50.7 \%)$ were para $1-2$, more than half of whom (20) had LES. As many as 46 (63.0\%) were traders only four of whom were high-income earners. Majority had low educational attainment. Economic status appeared to be directly proportional to the women's educational attainment as no participant with higher education had income below NGN50,000;

Eight (11.0\%) participants had received treatment elsewhere before reporting to the current hospital. Seven had one or more diagnosed co-morbidities. Significant post burn complications noted were unhealed wound/grafting 33 (45.2\%) and contracture 21 (28.8\%). More than half $39(53.4 \%)$ had two or more surgical

Table 1 Socio-demographic characteristics of participants $n=73$

\begin{tabular}{|c|c|c|}
\hline Personal characteristics & $\mathrm{N}$ & $\%$ \\
\hline \multicolumn{3}{|l|}{ Age (years) } \\
\hline $25-34$ & 28 & 38.4 \\
\hline $35-44$ & 26 & 35.6 \\
\hline$\geq 45$ & 19 & 26.0 \\
\hline \multicolumn{3}{|l|}{ Marital status } \\
\hline Married & 45 & 61.6 \\
\hline Single & 18 & 24.7 \\
\hline Widow & 10 & 13.7 \\
\hline \multicolumn{3}{|l|}{ Parity } \\
\hline Nulliparous & 18 & 24.7 \\
\hline Para 1-2 & 37 & 50.7 \\
\hline Para 3-4 & 8 & 11.0 \\
\hline$\geq 5$ & 10 & 13.7 \\
\hline \multicolumn{3}{|l|}{ Occupation } \\
\hline Civil Servant & 4 & 5.5 \\
\hline Self employed & 13 & 17.8 \\
\hline Trader & 46 & 63.0 \\
\hline homemaker & 10 & 13.7 \\
\hline \multicolumn{3}{|l|}{ Education } \\
\hline No formal & 18 & 24.7 \\
\hline Primary & 27 & 37.0 \\
\hline Secondary & 19 & 26.0 \\
\hline Higher & 9 & 12.3 \\
\hline \multicolumn{3}{|l|}{ Socio-economic status } \\
\hline Low $(<$ NGN 50,000) & 34 & 46.6 \\
\hline Middle (NGN50,000-NGN300,000) & 23 & 31.5 \\
\hline High (> NGN 300,000) & 12 & 16.4 \\
\hline Don't Know & 4 & 5.5 \\
\hline
\end{tabular}

interventions during management; only 5 (6.8\%) did not undergo surgery (Table 2).

\section{Monthly income and cost of hospitalization}

The women's average subjective monthly income prior to admission reduced drastically after hospitalization. With the support of participants' spouse and/or other family member(s) their average FMI before the burns marginally dropped at the end of hospitalization. The subjective average expenditure per day was NGN11,542 (USD32). With 35.4 days average LHS, the average total expenses incurred during hospitalization based on hospital bill at discharge and other estimated non-medical expenses related to hospitalization was NGN691,093 (USD1,920) (Table 3).

Eleven women and two caregivers respectively lost their job as a result of hospitalization. Out of these, seven were self-employed while four were traders (Fig. 2).

\section{Source of fund}

As indicated in Fig. 3, only 11 participants could bear all expenses involved in their care at family levels, whereas more than half were assisted by relations and friends. As many as 46 (63.0\%) sought loans from other sources for their treatment expenses. Twenty-six (35.6\%) sold; while only 4 (5.5\%) accessed the National Health Insurance Scheme (NHIS) for part payment of their cost of hospitalization. Not all values were exclusive as some participants had more than multiple source of fund.

Table 2 Other clinical history of participants $n=73$

\begin{tabular}{|c|c|c|c|}
\hline Personal characteristics & & Total & $\%$ \\
\hline Any treatment for the burns & Yes & 8 & 11.0 \\
\hline $\begin{array}{l}\text { prior to present hospitali- } \\
\text { zation }\end{array}$ & No & 65 & 89.0 \\
\hline Other co-morbidities (single & Hypertension & 6 & 8.2 \\
\hline 0 & Diabetes mellitus & 4 & 5.5 \\
\hline & Asthma & 1 & 1.4 \\
\hline & $\begin{array}{l}\text { Actual number of partici- } \\
\text { pants with co-morbidities }\end{array}$ & 7 & 9.6 \\
\hline Post burns status & Infection & 6 & 8.2 \\
\hline & Contracture & 21 & 28.8 \\
\hline & Itching at site of burn & 14 & 19.2 \\
\hline & Unhealed wound/grafting & 33 & 45.2 \\
\hline & Hypertrophic scar & 5 & 6.8 \\
\hline Number of surgeries done & None & 5 & 6.8 \\
\hline & 1 & 29 & 39.7 \\
\hline & $\geq 2$ & 39 & 53.4 \\
\hline
\end{tabular}


Table 3 Estimated monthly income and expenses due to hospitalization

\begin{tabular}{|c|c|c|c|c|}
\hline & & Self & $\begin{array}{l}\text { Spouse/others } \\
\text { in family }\end{array}$ & Total \\
\hline \multirow[t]{2}{*}{ Average income per month } & Before injury & NGN48,388 (USD134) & $\begin{array}{l}\text { NGN62,051 } \\
\text { (USD172) }\end{array}$ & $\begin{array}{l}\text { NGN1 10,439 } \\
\text { (USD307) }\end{array}$ \\
\hline & During admission & NGN23,750 (USD66) & $\begin{array}{l}\text { NGN59,612 } \\
\text { (USD166) }\end{array}$ & $\begin{array}{l}\text { NGN83,362 } \\
\text { (USD234) }\end{array}$ \\
\hline \multirow[t]{4}{*}{ Average expenses $(N)^{+}$} & Subjective average expenditure per day & - & - & $\begin{array}{l}\text { NGN11,542 } \\
\text { (USD32) }\end{array}$ \\
\hline & Average medical expenses (A) & - & - & $\begin{array}{l}\text { NGN549,142 } \\
\text { (USD1,526) }\end{array}$ \\
\hline & Average of other (non-medical) expenses (B) & - & - & $\begin{array}{l}\text { NGN134,287 } \\
\text { (USD373) }\end{array}$ \\
\hline & Average total expenses $(A+B)$ & - & - & $\begin{array}{l}\text { NGN691,093 } \\
\text { (USD1,920) }\end{array}$ \\
\hline Average LHS & & - & - & 35.4 days \\
\hline
\end{tabular}

${ }^{+}$Dollar equivalents are approximated to whole numbers (at NGN360/USD exchange rate)

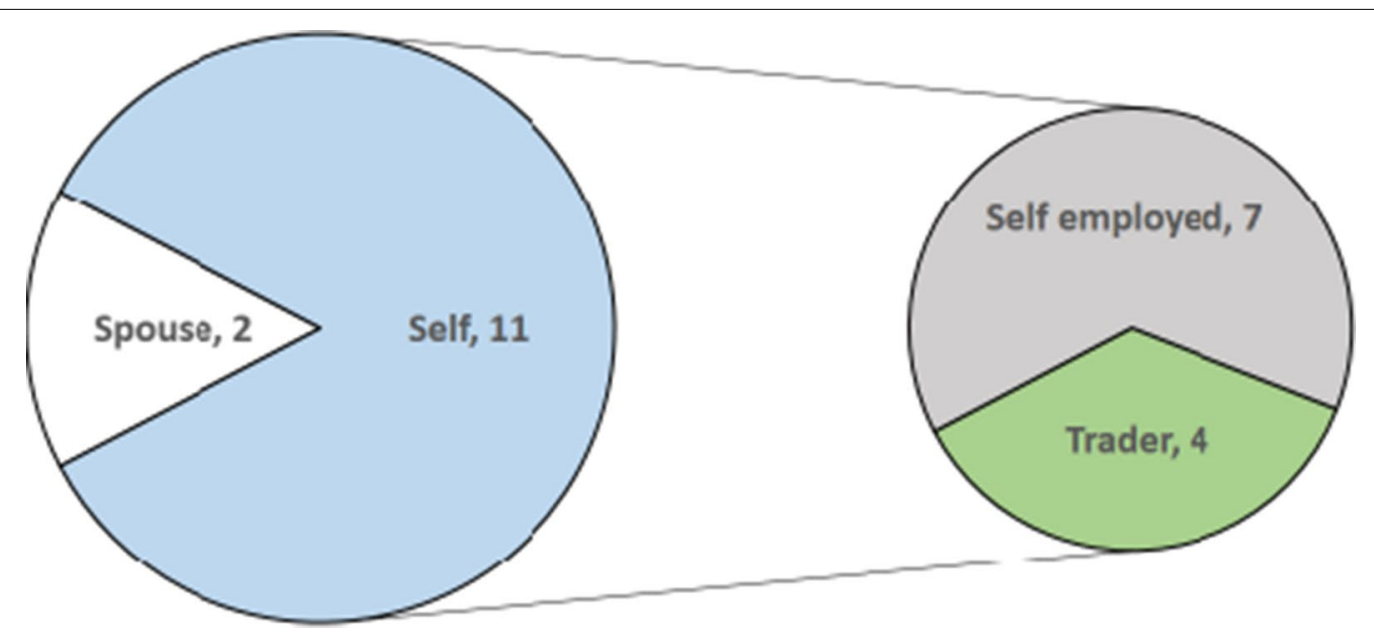

Fig. 2 Loss of job as a result of hospitalization

\section{Economic burden}

Half of the participants 37 (50.7\%) had their economy moderately worsened following hospitalisation, while 23 $(31.5 \%)$ had severe degree of worsening. However, analysis of variance of the scores showed no significant difference in the degree of economic worsening the women had post hospitalization based on their economic status $(\mathrm{F}=1.101 ; \mathrm{p}=0.355)$ (Table 4).

\section{Participants' health-related quality of life}

Data from the seven (7) participants with clinically diagnosed co-morbidities (three participants had combine co-morbidities) were deliberately excluded before analysis to eliminate the possible confounding effect of these co-morbidities on their HRQOL scores; hence, data from 66 participants were analysed. Analysis of the participants' report on the EQ-5D-3L by dimension and level (Fig. 4) showed that the least of their problems were mobility and performance of usual activities. About three quarters of the respondents each reported anxiety/depression 51 (77.3\%), pain/discomfort 50 (75.8\%) and problems with self care 49 (74.2\%).

Table 5 showed that anxiety/depression was the greatest problem reported by the women. However, the anxiety/depression varied significantly according to their marital status, SES, occupation and education $(\mathrm{p}<0.05)$. They reported problems with mobility and self-care irrespective of their marital status, parity, SES, occupation and education. Specifically, younger women had less problem with mobility while the older women had higher problems $(\mathrm{p}=0.000)$. Similarly, the women's report on pain/discomfort differed significantly according to their SES $(p=0.000)$, education $(p=0.000)$ and 


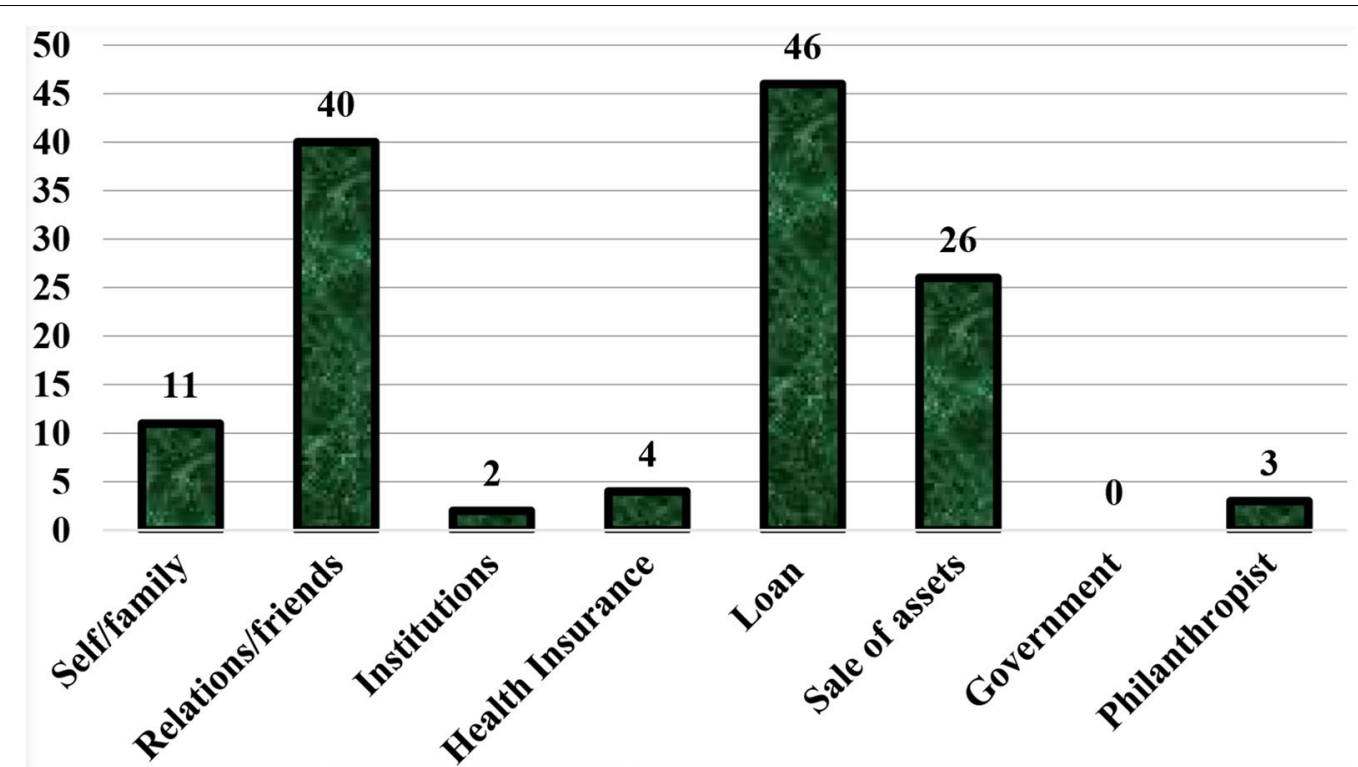

Fig. 3 Source of fund for medical and non-medical expenses

Table 4 ANOVA of subjective degree of economic worsening due to hospitalisation $\boldsymbol{n}=73$

\begin{tabular}{|c|c|c|c|c|c|c|c|c|}
\hline \multirow{2}{*}{$\begin{array}{l}\text { Degree of economic } \\
\text { worsening }\end{array}$} & \multirow[t]{2}{*}{$\mathbf{N}$} & \multicolumn{4}{|c|}{ Economic status } & \multicolumn{3}{|l|}{ ANOVA result } \\
\hline & & Low 34 (\%) & Middle 24 (\%) & High 10\%) & $\begin{array}{l}\text { Don't know } \\
5(\%)\end{array}$ & Sum of squares & $\begin{array}{l}\text { df, } \\
F\end{array}$ & Sig \\
\hline Severe & $\begin{array}{l}23 \\
(31.5)\end{array}$ & $\begin{array}{l}15 \\
(65.2)\end{array}$ & $\begin{array}{l}5 \\
(21.7)\end{array}$ & $\begin{array}{l}1 \\
(4.3)\end{array}$ & $\begin{array}{l}2 \\
(8.7)\end{array}$ & 2.801 & $\begin{array}{l}3 \\
1.101\end{array}$ & 0.355 \\
\hline Moderate & $\begin{array}{l}37 \\
(50.7)\end{array}$ & $\begin{array}{l}15 \\
(40.5)\end{array}$ & $\begin{array}{l}11 \\
(29.70\end{array}$ & $\begin{array}{l}8 \\
(21.6)\end{array}$ & $\begin{array}{l}3 \\
(8.1)\end{array}$ & & & \\
\hline A little & $\begin{array}{l}9 \\
(12.3)\end{array}$ & $\begin{array}{l}2 \\
(22.2)\end{array}$ & $\begin{array}{l}6 \\
(66.7)\end{array}$ & $\begin{array}{l}1 \\
(11.1)\end{array}$ & - & & & \\
\hline Not at all & $\begin{array}{l}4 \\
(5.5)\end{array}$ & $\begin{array}{l}2 \\
(50.0)\end{array}$ & $\begin{array}{l}2 \\
(50.0)\end{array}$ & - & - & & & \\
\hline
\end{tabular}

occupation $(\mathrm{p}=0.002)$. With overall EQ-5D mean score of 2.04, that is $>2$, participants' HRQOL was considered as generally poor.

Analysis of the reports on the EQ-5D-3L VAS 'health state today' (Table 6$)$ showed a mean $( \pm$ SD) of $57.12 \pm 19.436$. Specifically, as many as 15 participants reported an EQ VAS of 50-which incidentally was the median of the scores. The women's EQ VAS 'health state today' varied significantly according to their SES $(\mathrm{p}<0.002)$. The scores appeared to improve as the SES increased; thus, women of LES had mean $( \pm S D)$ VAS score as low as $53.33 \pm 17.619$, median $=50$; which increased to $76.67 \pm 21.794$, median $=90$ for the HES.

Multiple comparison of the scores on the EQ-5D-3L HRQOL using Tukey HSD Repeated Mean test show that the variations in SES were less for anxiety but were unequal guaranteeing Type 1 error (Table 7).

\section{Discussions}

This study determined the burden of hospitalization after burns on women's economic status and its associated HRQOL. The women had worsened economy post burn treatment due to high cost of hospitalization, loss of job and indebtedness. According to results of this study, a client spends as high as NGN691,093 (USD1,920) on the average on drugs, surgery, investigations, nursing care, bed space and other non-medical expenses (like feeding, transportation and procurement of toiletries). This is similar to $\$ 2,810$ and $\$ 2,766$ reported by Karimi [13] and Latifi et al. [14] respectively, but far below $\$ 7,123.28$ 


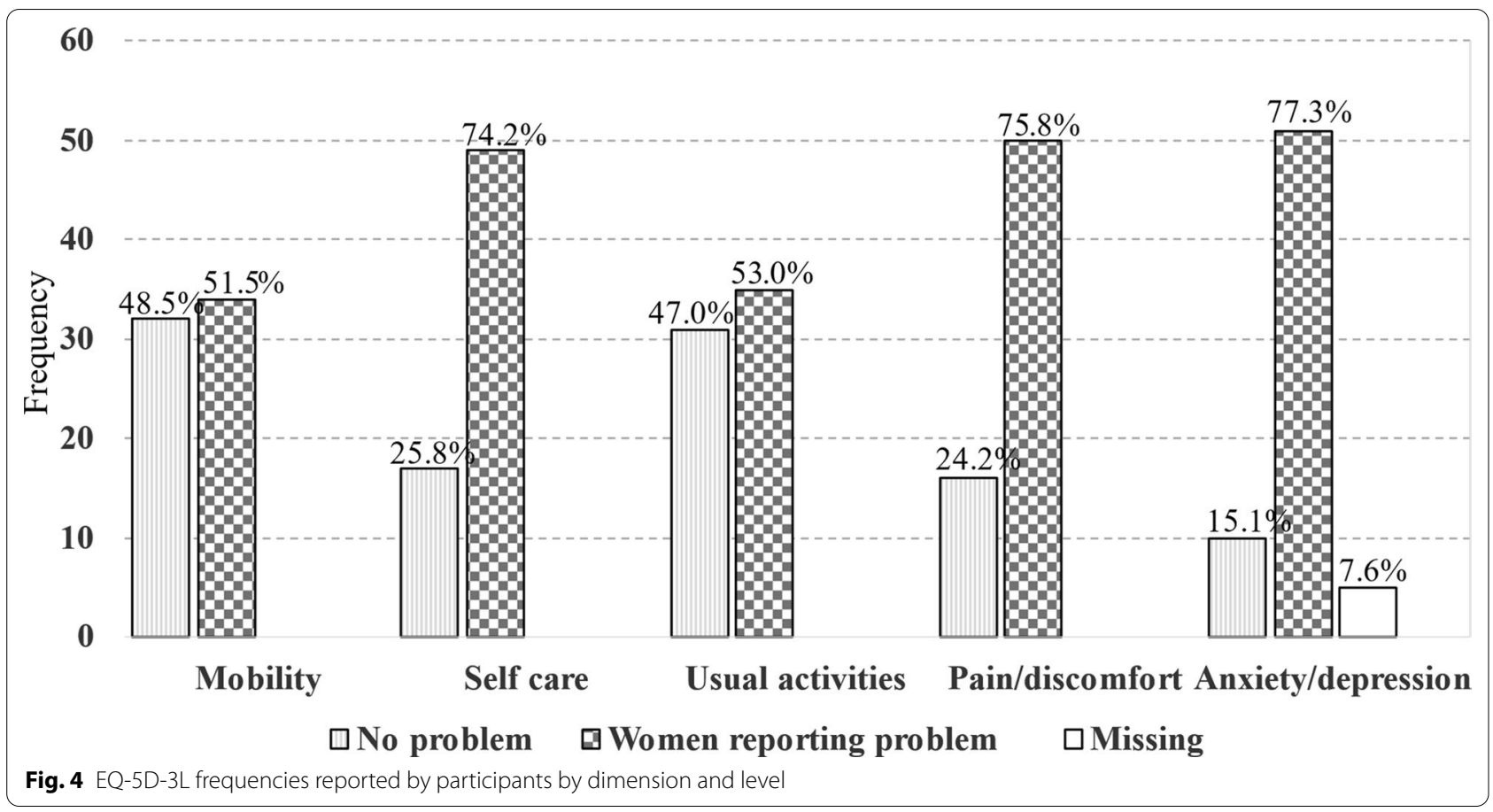

estimated by Okafor et al. [4]. Meanwhile, the average LHS was 35.4 days-against the 19 days average found by Okafor et al. [4]; and FMI before the burns was just about $11.1 \%$ of the hospital expenses. Unfortunately, only $5.5 \%$ accessed the services of the NHIS. The near non-existed NHIS as already demonstrated [17-19] is thus supported by findings of this study. Poor health financing has pitiable implications for achievement of goals of universal health coverage in Nigeria.

Result of this study showed that although it was done in an urban setting, most of the participants were young, fairly educated, married women of low means, mainly traders or homemakers. Many of them had moderate to severe burden of treatment because of the high cost of treatment. Result indicated that as many as thirty-three were discharged home with open wounds and/or grafting possibly to avoid further accumulation of hospital bill. This finding directly reflects the low economic capacity of most of the women and the fact that most expenditure are out-of-pocket as they reported. Almost all the participants (68) had at least one surgical intervention during their burns management, meaning that burns patients will often need huge amount of money for operation and drugs deposits. In addition, they will require fund to procure the expensive modern dressing applications (like the Epigraft, Ex salt T7 and Therabond applications), high protein diet peculiar to burns treatment as well as pay for orthodox dressing change. If patient fails to pay for drugs, then drugs supply by the Pharmacy Department may be withdrawn. Unfortunately, antibiotics used in burns treatment are usually costly (like the injection Meronem that sells between N6,000.00 to N8,000.00 per vial) and procuring such may be challenging to the patient, resulting to more burden.

The estimated family income can only yield about $20.89 \%$ of the average total expenses incurred during hospitalization, all things being equal; meaning that the remaining $79.11 \%$ must be sourced elsewhere. Our study showed that there was worsening of economy for most of the women following hospitalization irrespective of their economic status, and that up to eleven women, mostly traders and self-employed women, lost their job due to hospitalization. Since many of the participants were women of low means, they were most likely to be sole traders operating easy and inexpensive business with unstable customers and finance. The reported drop in estimated subjective monthly income supports the fact that even the usual meagre income will stop flowing in when the woman is hospitalised. Consequently, many would secure loans from friends, money lenders, bank, cooperative society, and the likes (with interest in some situations) and/or mortgage/sell assets such as lands, automobile, power generating set, television, jewelleries and clothes to raise fund for offsetting the huge hospital bills. Borrowing, selling personal assets and sometimes, loss of job are catastrophic results of the injury. Resultant stress and financial hardship/burden for the women and 
Table 5 EQ-5D-3L utility scores dimensions of participants' HRQOL according to their socio-demographic characteristicsn $=66$

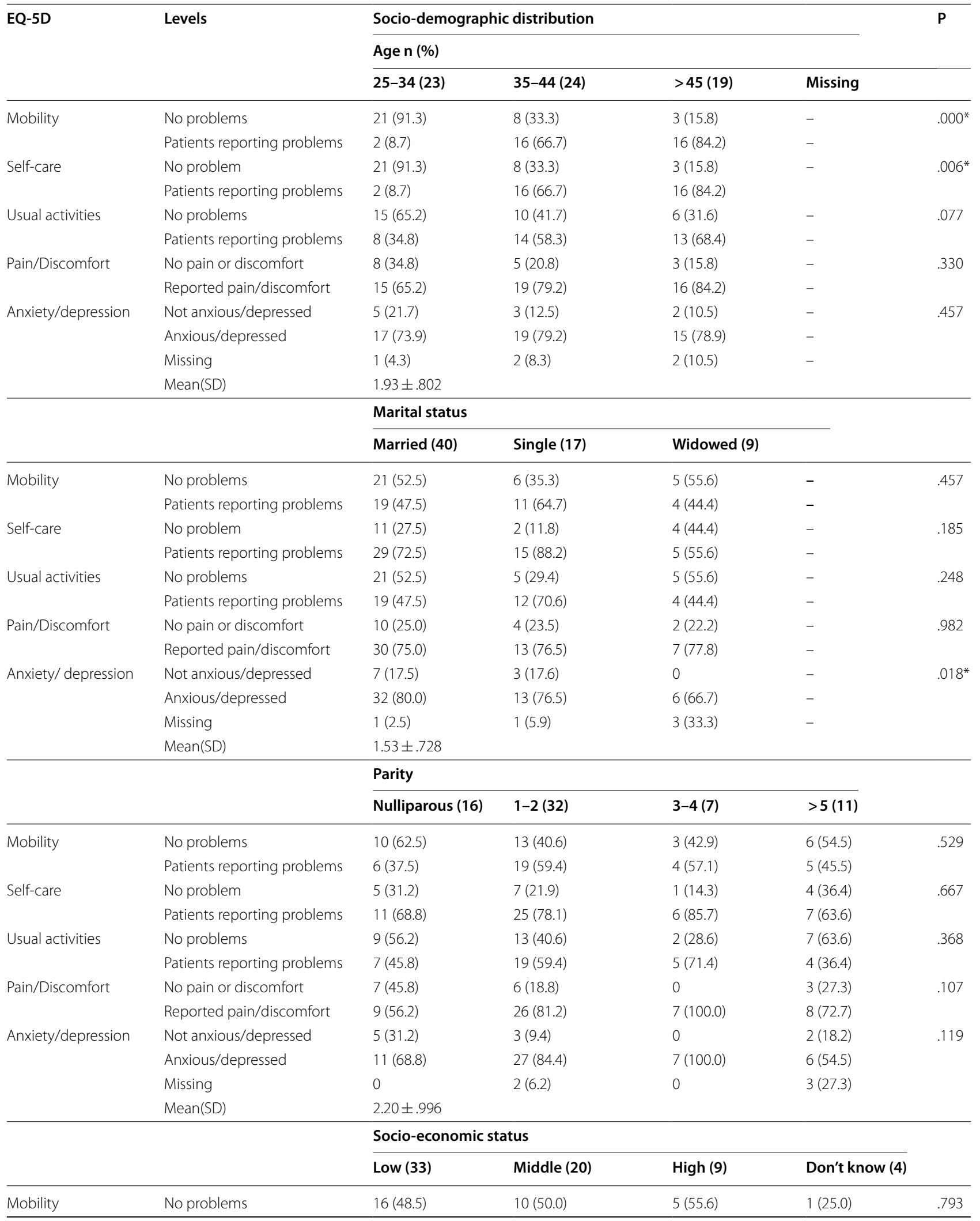


Table 5 (continued)

\begin{tabular}{|c|c|c|c|c|c|c|}
\hline & & \multicolumn{4}{|c|}{ Socio-economic status } & \\
\hline & & Low (33) & Middle (20) & High (9) & Don't know (4) & \\
\hline & Patients reporting problems & $17(51.5)$ & $10(50.0)$ & $4(44.4)$ & $3(75.0)$ & \\
\hline \multirow[t]{2}{*}{ Self-care } & No problem & $6(18.2)$ & $7(35.0)$ & $3(33.3)$ & $1(25.0)$ & .557 \\
\hline & Patients reporting problems & $27(81.8)$ & $13(65.0)$ & $6(66.7)$ & $3(75.0)$ & \\
\hline \multirow[t]{2}{*}{ Usual activities } & No problems & $11(33.3)$ & $13(65.0)$ & $6(66.7)$ & $1(25.0)$ & .064 \\
\hline & Patients reporting problems & $22(66.7)$ & $7(35.0)$ & $3(33.3)$ & $3(75.0)$ & \\
\hline \multirow[t]{2}{*}{ Pain/Discomfort } & No pain or discomfort & $2(6.1)$ & $8(40.0)$ & $6(66.7)$ & 0 & $.000^{*}$ \\
\hline & Reported pain/discomfort & $31(93.9)$ & $12(60.0)$ & $3(33.3)$ & $4(100.0)$ & \\
\hline \multirow[t]{6}{*}{ Anxiety/ depression } & Not anxious/depressed & $1(3.0)$ & $5(25.0)$ & $4(44.4)$ & 0 & $.000^{*}$ \\
\hline & Anxious/depressed & $29(87.9)$ & $15(75.0)$ & $5(55.6)$ & $2(50.0)$ & \\
\hline & Missing & $3(9.1)$ & 0 & 0 & $2(50.0)$ & \\
\hline & Mean(SD) & \multicolumn{4}{|l|}{$1.76 \pm .913$} & \\
\hline & & \multicolumn{4}{|l|}{ Occupation } & \\
\hline & & Civil Servant (4) & Self employed (12) & Trader (41) & Housewife (9) & \\
\hline \multirow[t]{2}{*}{ Mobility } & No problems & $1(25.0)$ & $7(58.3)$ & $21(51.2)$ & $3(33.3)$ & .529 \\
\hline & Patients reporting problems & $3(75.0)$ & $5(41.7)$ & $20(48.8)$ & $6(66.7)$ & \\
\hline \multirow[t]{2}{*}{ Self-care } & No problem & $1(25.0)$ & $1(8.3)$ & $13(31.7)$ & $2(22.2)$ & .452 \\
\hline & Patients reporting problems & $3(75.0)$ & $11(91.7)$ & $28(68.3)$ & $7(77.8)$ & \\
\hline \multirow{2}{*}{ Usual activities } & No problems & $4(100.0)$ & $5(41.7)$ & $18(43.9)$ & $4(44.4)$ & .191 \\
\hline & Patients reporting problems & 0 & $7(58.3)$ & $23(56.1)$ & $5(55.6)$ & \\
\hline \multirow[t]{2}{*}{ Pain/Discomfort } & No pain or discomfort & $3(75.0)$ & $6(50.0)$ & $7(17.1)$ & 0 & $.002^{*}$ \\
\hline & Reported pain/discomfort & $1(25.0)$ & $6(60.0)$ & $34(82.9)$ & $9(100.0)$ & \\
\hline \multirow[t]{6}{*}{ Anxiety/ depression } & Not anxious/depressed & $2(50.0)$ & $4(33.3)$ & $4(9.8)$ & 0 & $.023^{*}$ \\
\hline & Anxious/depressed & $2(50.0)$ & $8(66.7)$ & $33(80.5)$ & $8(88.9)$ & \\
\hline & Missing & 0 & 0 & $4(9.7)$ & $1(11.1)$ & \\
\hline & Mean(SD) & \multicolumn{5}{|l|}{$2.63 \pm .7 .355$} \\
\hline & & \multicolumn{4}{|l|}{ Education } & \\
\hline & & No formal (15) & Primary (27) & Secondary (13) & Higher (11) & \\
\hline \multirow[t]{2}{*}{ Mobility } & No problems & $8(53.3)$ & $11(40.7)$ & $6(46.2)$ & $7(63.6)$ & .625 \\
\hline & Patients reporting problems & $7(46.7)$ & $16(59.3)$ & $7(53.8)$ & $4(36.4)$ & \\
\hline \multirow[t]{2}{*}{ Self-care } & No problem & $4(26.7)$ & $4(14.8)$ & $5(38.5)$ & $4(36.4)$ & .341 \\
\hline & Patients reporting problems & $11(73.3)$ & $23(85.2)$ & $8(61.5)$ & $7(63.6)$ & \\
\hline \multirow[t]{2}{*}{ Usual activities } & No problems & $5(33.3)$ & $10(37.0)$ & $7(53.9)$ & $9(81.8)$ & $.049^{*}$ \\
\hline & Patients reporting problems & $10(66.7)$ & $17(63.0)$ & $6(46.2)$ & $2(18.2)$ & \\
\hline \multirow[t]{2}{*}{ Pain/discomfort } & No pain or discomfort & 0 & $3(11.1)$ & $3(23.1)$ & $10(90.9)$ & $.000^{*}$ \\
\hline & Reported pain/discomfort & $15(100.0)$ & $24(88.9)$ & $10(76.9)$ & $1(9.1)$ & \\
\hline \multirow[t]{4}{*}{ Anxiety/depression } & Not anxious/depressed & 0 & $1(3.7)$ & $1(7.7)$ & $8(72.7)$ & $.000^{*}$ \\
\hline & Anxious/depressed & $12(80.0)$ & $25(92.6)$ & $11(84.6)$ & $3(27.3)$ & \\
\hline & Missing & $3(20.0)$ & $1(3.7)$ & $1(7.7)$ & 0 & \\
\hline & Mean(SD) & $2.20 \pm 1.007$ & & & & \\
\hline Grand Mean & & 2.04 & & & & \\
\hline
\end{tabular}

*Significance

their family will deepen the pre-existing low economic standard.

Further, the women's HRQOL was poor as they reported anxiety/depression, self-care deficit and physical discomfort, thus aligning with Spronk [8]. Also, their EQ VAS and anxiety/depression scores differed significantly based on their occupation. Civil servants' highest scores on the EQ VAS imply a better quality of life among them. 
Table 6 Participants' reports on the EQ VAS according to their SES $\boldsymbol{n}=\mathbf{6 6}$

\begin{tabular}{|c|c|c|c|c|c|c|}
\hline \multirow[t]{2}{*}{ EQ VAS score (n) } & \multirow[b]{2}{*}{$\begin{array}{l}\text { Low } \\
33(\%)\end{array}$} & \multicolumn{4}{|c|}{ Economic Status } & \multirow[t]{2}{*}{$\mathrm{P}^{\dagger}$} \\
\hline & & $\begin{array}{l}\text { Middle } \\
20(\%)\end{array}$ & $\begin{array}{l}\text { High } \\
9(\%)\end{array}$ & Don't know 4 (\%) & Total & \\
\hline 10 & - & - & - & - & 0 & $.002^{*}$ \\
\hline 20 & - & - & - & - & 0 & \\
\hline 30 & $5(15.2 \%)$ & $3(15.0 \%)$ & $1(11.1 \%)$ & $2(50.0 \%)$ & 11 & \\
\hline 40 & $7(21.2 \%)$ & - & 0 & $1(25.0 \%)$ & 8 & \\
\hline 50 & $8(24.3 \%)$ & $6(30.0 \%)$ & $1(11.1 \%)$ & - & 15 & \\
\hline 60 & $5(15.2 \%)$ & $4(20.0 \%)$ & 0 & $1(25.0 \%)$ & 10 & \\
\hline 70 & $3(9.1 \%)$ & $3(15.0 \%)$ & 0 & - & 6 & \\
\hline 80 & $3(9.1 \%)$ & $4(20.0 \%)$ & $2(22.2 \%)$ & - & 9 & \\
\hline 90 & $2(6.1 \%)$ & 0 & $5(55.6 \%)$ & - & 7 & \\
\hline 100 & - & - & - & - & 0 & \\
\hline Mean $( \pm S D)$ VAS & $53.33 \pm 17.619$ & $58.00 \pm 16.416$ & $76.67 \pm 21.794$ & $40.00 \pm 14.142$ & $57.12 \pm 19.436$ & \\
\hline Median & 50 & 60 & 90 & 35 & 50 & \\
\hline
\end{tabular}

${ }^{\dagger}$ 1-Way ANOVA P value

*Significant

Conversely, the highest anxiety/depression scores for the self-employed women mean poorer HRQOL. Civil servants work in domesticated organisations-they have little or no worry concerning the impact of hospitalization on their job because their job is secured. Self-employed women and traders, on the other hand, operate as 'wild' organisations because they always have to struggle for their own survival. Based on this, civil servants are more likely to have more positive assessment of their health state at any time than the self-employed and traders.

The women's anxiety/depression dimension and EQ VAS varied based on their economic status. Although

Table 7 Tukey HSD post-hoc test of homogeneity of the scores on EQ-5D-3L and EQ VAS of HRQOL

\begin{tabular}{llllc}
\hline Quality of life scale & SES & \multicolumn{3}{c}{$\begin{array}{l}\text { Subset for alpha } \\
\text { on the EQ-5D-3L= }\end{array}$} \\
\cline { 3 - 5 } & & $\mathbf{1}$ & $\mathbf{2}$ & $\mathbf{3}$ \\
\hline Pain/discomfort & High SES (9) & 1.556 & - & - \\
& Middle SES (20) & 1.700 & - & - \\
& Low SES (33) & 2.303 & - & - \\
& Don't know (4) & 2.250 & - & - \\
Anxiety/depression & High SES (9) & 1.667 & - & - \\
& Middle SES (20) & 1.950 & 1.950 & - \\
& Low SES (33) & - & 2.636 & 2.636 \\
& Don't Know (4) & - & - & 3.250 \\
& High SES (9) & 3.222 & - & - \\
& Middle SES (20) & 2.600 & - & - \\
& Low SES (33) & 2.121 & - & - \\
& Don't Know (4) & 3.000 & - & - \\
\hline
\end{tabular}

there was no significant difference in other EQ-5D-3L dimensions, women in the LES appeared to be more inclined to extreme anxiety or depression than the middle and high economic class. Tucker et al. [9] earlier reported this downward health trajectory for women with high economic hardship. With insufficient fund, making required deposits for treatments and surgeries, paying for expensive drugs, dressing packs and other medical and non-medical needs will become difficult.

It is understandable that a good number of the women reported 'extreme pain or discomfort' or 'confinement to bed after long stay in hospital' or inability to perform usual activities independently because burns is ordinarily characterised with pain. Some women may have requested for 'pre-mature' discharge (even with open wound and partially healed grafting) to reduce further accumulation of hospital bill. Patients are not supposed to be discharged until they are fully recovered and capable of performing most activities of daily living unassisted. Sick patients in hospital have their sick role; the health conditions are continuously monitored while their skilled care providers institute necessary actions. When the individual is discharged home before full recovery, self-dependence and perhaps care by unskilled caregivers becomes the available option. This comes with its risk of wound breakdown, infection, pain and other complications, further worsening the already poor HRQOL and high economic burden of treatment.

There was significant difference between the women's age and their mobility, self-care and usual activities. As earlier observed by Chinweuba et al. [10], the older women had poorer mobility and less ability to perform 
usual activities than the younger women did. This is understandable because people are physically stronger, more active and better able to self-manage their problems at their youthful age and become weaker as they get old. Young women may also have less social responsibilities and fewer challenges with self-care. Increasing level of education tends to reduce the women's anxiety levels probably because it (education) will enhance better understanding of one's challenges, better-informed decision making and more focused health actions. Educated women will be better able to study and understand their problem and its management than their less educated counterparts.

Result showed significant difference in the women's pain/discomfort dimension based on their parity. However, there was not any specific pattern in the differences. More studies may be required on this.

\section{Strengths and limitations}

One strength of this study is the choice of patients with moderate to severe degrees of burn which allowed for full range assessment of impact of burn injury and its management. Women with varying economic status entered the study. This served the opportunity to measure how SES predict the HRQOL of the patients. Although this study was done in Nigeria, the evident data may be resourceful in countries with similar "burn" problems for health policy decision making. However, the study was constrained by paucity of related literature especially from other low- to medium-income countries for a better view and understanding of economic burden of hospitalization after burns. Non-medical expenses related to hospitalization were estimates that were liable to personal factors of the participants. The values, therefore, cannot be used reliably as standard in similar studies.

\section{Conclusion}

Burns place high level of economic burden to the women who are predominantly of LES. It also has enormous negative impact on their quality of life. Many of them do not recover fully before leaving the hospital. The women's HRQOL is directly proportional to their economic status and degree of economic burden. The long course of treatment and economic depletion through the huge out-ofpocket expenditure impact negatively on their HRQOL. Pain/discomfort, 'reduced mobility and activities' and anxiety/depression are commonly affected dimensions of the women's HRQOL following burns. The women's level of education is directly proportional to their HRQOL. Nigerian government's commitment to healthcare of burns patients is low or non-existent.

Based on the findings, we recommended that State and national governments create special trust fund for treatment, or at least subsidize treatment of burns particularly for indigent patients with severe burns, where free treatment is not possible. The NHIS needs to be made more accessible to all categories of the citizenry. We also recommend formation of non-profit burns foundations by non-governmental agencies with special endowment funds to assist financing of burns treatment. Finally, female education should be made free and compulsory in Nigeria with secondary school as the minimum.

\section{Supplementary Information}

The online version contains supplementary material available at https://doi. org/10.1186/s12905-021-01232-5.

Additional file 1. Economic Burden of Burns Questionnaire (EBB-Q).

\section{Abbreviations}

ANOVA : Analysis of Variance; EBB-Q : Economic Burden of Burns Questionnaire; EQ VAS: Visual Analogue Scale; EQ-5D-3L: EuroQol Five-DimensionsThree-Level; FMI: Family Monthly Income; HES: High Economic Status; HRQOL: Health-related Quality of Life; LES: Low Economic Status; LHS: Length of Hospital Stay; MES: Middle Economic Status; NGN: Nigeria Naira; NHIS: National Health Insurance Scheme; QALYs: Quality-Adjusted Life Years; USD: United States Dollar; WHO: World Health Organisation.

\section{Acknowledgements}

Not applicable.

\section{Authors' contributions}

AUC conceived the paper, prepared the study protocol, designed the study, drafted the manuscript, and contributed to the statistical analysis and interpretation; ISC participated in project administration, data interpretation and critical revision of the manuscript; NEU contributed in drafting the manuscript and supervision of data analysis. KBW contributed in literature review, writing the manuscript and discussion; CSE assisted in interpretation of the data, contributed to the discussion and edited the manuscript; FCD participated in drafting the manuscript and the discussion. AIN participated in the acquisition of the data and contributed to supervision of data. All authors participated in data collection and critically reviewed the manuscript for important intellectual content and approved the final manuscript.

\section{Funding}

This study was not supported by any grant. The study design; data collection, analysis and interpretation of data; writing of the paper; and the decision to submit the paper for publication were, therefore, sole responsibility of the authors.

\section{Availability of data and materials}

The datasets generated and/or analysed during the current study are not publicly available because some parts of the data contain confidential personal information of respondents and their family, but are available from the corresponding author on reasonable request.

\section{Ethics approval and consent to participate}

Ethical approval was obtained from the Ethical Review Committee of the National Orthopaedic Hospital, Enugu (IRB/HEC Number: RET/313/111/988). Written informed consent was obtained from participants before their enrolment.

\section{Consent for publication}

Not applicable.

Competing interests

The authors declare that they have no competing interests. 


\section{Author details}

${ }^{1}$ Department of Nursing Sciences, Faculty of Health Sciences and Technology, College of Medicine, University of Nigeria, Enugu Campus, Enugu, Nigeria.

${ }^{2}$ Department of Medicine and Surgery, College of Medicine, Chukwuemeka Odumegwu Ojukwu University, Awka, Anambra State, Nigeria. ${ }^{3}$ Department of Nursing Sciences, University of Port Harcourt, Rivers State, Port Harcourt, Nigeria. ${ }^{4}$ Department of Nursing Science, Ebonyi State University, Abakaliki, Ebonyi State, Nigeria. ${ }^{5}$ Faculty of Nursing Sciences, College of Health Sciences, Niger Delta University, Wilberforce Island, Bayelsa State, Nigeria. ${ }^{6}$ School of Nursing, University of Nigeria Teaching Hospital, Enugu, Enugu State, Nigeria.

Received: 23 April 2020 Accepted: 21 February 2021

Published online: 28 February 2021

\section{References}

1. Institute for Health Metrics and Evaluation. The Global Burden of Disease: 2010 Update. IHME, Seattle. www.healthmetricsandevaluation.org/gbdcompare/. Accessed 7 June 2019

2. WHO. Burns. https://www.who.int/news-room/fact-sheets/detail/burns (6 March 2018). Accessed 24 Aug 2019

3. Ogbogu CJ, Uduezue A, Anetekhai WI, Agunwa CC. Burn injuries in pregnancy in a regional burns center in Nigeria: presentation. Matern Fetal Outcome Burns Open. 2018;2:53-8. https://doi.org/10.1016/j.burns 0.2017 .11 .001

4. Okafor CE, Onunka O, Idoko LN. Cost-utility of burns management in Nigeria: a case study of the National Orthopaedic Hospital, Enugu. Ann Burns Fire Disasters. 2017;30(1):9-12.

5. Chukuezi C. Socio-cultural factors associated with maternal mortality in Nigeria. Res J Soc Sci. 2010;1 (5):22-6.

6. Fox JK, Halpern LF, Ryan JL, Lowe KA. Stressful life events and the tripartite model: relations to anxiety and depression in adolescent females. J Adolesc. 2010:33(1):43-54. https://doi.org/10.1016/j.adolescence.2009.05.009.

7. Enyioha S. Ile Omugwo: Igbo women and social status. 2011. http://enyioha-one-of-naiji.blogspot.com/2011/04/ile-omugwo.html on 25th May, 2019. Accessed 24 Aug 2019.

8. Spronk I, Legemate CM, Dokter J, et al. Predictors of health-related quality of life after burn injuries: a systematic review. Crit Care. 2018;22:160. https ://doi.org/10.1186/s13054-018-2071-4.

9. Tucker JN, Grzywacz JG, Leng I, Clinch CR, Arcury TA. Return to work, economic hardship, and women's postpartum health. Women Health 2010;50(7):618-38. https://doi.org/10.1080/03630242.2010.522468.

10. Chinweuba AU, Okoronkwo IL, Anarado AN, Agbapuonwu NE, Ogbonnaya NP, Ihudiebube-Splendor CN. Differentials in health-related quality of life of employed and unemployed women with normal vaginal delivery. BMC Womens Health. 2018. https://doi.org/10.1186/s1290 5-017-0481-0.

11. Greenberg M. Real housewives \& black swan: Too rich \& too thin? Psychology Today. 2011 http://www.psychologytoday.com/blog/the-mind ul-self-express/201 102/real-housewives-black-swan-too-rich-too-thin. Accessed 25 May 2019.

12. Gallacher KI, May CR, Langhorne P, Mair FS. A conceptual model of treatment burden and patient capacity in stroke. BMC Fam Pract. 2018;19:9. https://doi.org/10.1186/s12875-017-0691-4.

13. Karimi H, Motevalian SA, Momeni M, Ghadarjani M. Financial burden of burn injuries in Iran: a report from the burn registry program. Ann Burns Fire Disasters. 2015:28(4):310-4.

14. Latifi NA, Karimi KF, Motevallian SA, Momeni M. Economical burden of burn injuries in a developing country. J Burn Care Res. 2017;38(6):e900-5. https://doi.org/10.1097/BCR.0000000000000515.
15. Onah II, Achebe JU, Iheuko SO. Burn disaster acute care management in a Nigerian hospital: any change 10 years after? Niger J Med. 2012;21(3):361-2.

16. Omomia O. Lack of mandatory participation in the NHIS Act Impeding Growth of Health Insurance Coverage in Nigeria. Business Day Online. 2018 March 29. https://www.businessdayonline.com/research-reports/ article/lack-mandatory-participation-nhis-act-impeding-growth-healt h-insurance-coverage-nigeria/. Accessed 8 Aug 2019

17. Olakunde BO. Public health care financing in Nigeria: which way forward? Ann Nigerian Med. 2012;6(1):4-10. https://doi.org/10.4103/03313131.100199.

18. Campbell C. Failures of Nigerian Health Insurance Scheme: the way forward. The Guardian. 2018, January 18 https://guardian.ng/features/ science/failures-of-nigerian-health-insurance-scheme-the-way-forward/. Accessed 17 May 2019

19. Muanya C. Many lapses in NHIS implementation. The Guardian. 2017, June 29 https://guardian.ng/features/science/many-lapses-in-nhis-imple mentation/. Accessed 17 May 2019

20. Dokunmu TM, Adjekukor CU, Oladejo D, Amoo EO. Dataset on analysis of quality of health and social insurance subscription in different socioeconomic class of workers in selected areas in southwest Nigeria. Data Brief. 2018;21:1286-91. https://doi.org/10.1016/j.dib.2018.10.135.

21. Abbott TEF, Fowler AJ, Dobbs TD, Harrison EM, Gillies MA, Pearse RM. Frequency of surgical treatment and related hospital procedures in the UK: A national ecological study using hospital episode statistics. BJA Br J Anaesthesia. 2017;119(2):249-57. https://doi.org/10.1093/bja/aex137.

22. Bittner EA, Shank E, Woodson L, Jeevendra-Martyn JA. Acute and perioperative care of the burn-injured patient. Anesthesiology. 2016;122(2):44864. https://doi.org/10.1097/ALN.0000000000000559.

23. Saaiq M, Zaib S, Ahmad S. The menace of post-burn contractures: a developing country's perspective. Ann Burns Fire Disasters. 2012;25(3):152-8.

24. Shahid F, Ismail M, Khan S. Assessment of quality of life in post burn survivors: a cross-sectional single-center first validation study from Pakistan. Burns Open. 2018;2(1):35-42. https://doi.org/10.1016/j.burns 0.2017 .08 .003 .

25. McCaffrey N, Kaambwa B, Currow DC, Ratcliffe J. Health-related quality of life measured using the EQ-5D-5L: South Australian population norms. Health Qual Life Outcomes. 2016;14:133. https://doi.org/10.1186/s1295 5-016-0537-0.

26. Creative Research Systems Sample size calculator (n.d.). Your complete systems survey software solution n.d. https://www.surveysystem.com/ sscalc.htm. Accessed 7 Apr 2020.

27. ANGEL STAT 509. Design and analysis of clinical trials. Lesson 6: Sample size and power n.d.. Retrieved from https://onlinecourses.science.psu. edu/stat509/node/57. Accessed 7 Apr 2020.

28. Deshpande ON, Puri V, Vora SS, Shende NN, Choudhary SC. Socio-economic burden of burns: how do the families of patients cope? Indian J burns. 2012;20(1):48-52. https://doi.org/10.4103/0971-653X.111783.

29. Oster C, Willebrand M, Dyster-Aas J, Kildal M, Ekselius L. Validation of the EQ-5D questionnaire in burn injured adults. Burns. 2009;35(5):723-32. https://doi.org/10.1016/j.burns.2008.11.007.

30. Euroqol Research Foundation. EQ-5D-3L User guide: basic information on how to use the EQ-5D-3L Instrument. 2018). https://euroqol.org/ wp-content/uploads/2019/10/EQ-5D-3L-User-Guide_version-6.0.pdf. Accessed 7 Jan 2021

\section{Publisher's Note}

Springer Nature remains neutral with regard to jurisdictional claims in published maps and institutional affiliations. 